\title{
LA MISIÓN DEL BANCO MUNDIAL A COLOMBIA DE 1949, Y LAS VISIONES OPUESTAS DE LAUCHLIN CURRIE Y ALBERT HIRSCHMAN
}

Roger Sandilands*

Oomo relata en detalle Alacevich (2009), Lauchlin Currie (19021993) fue escogido en 1949 para dirigir la primera de las misiones de estudios integrales del Banco Mundial en Colombia (ver también Sandilands, 1990). Después de presentar su Informe, Currie regresó a Colombia para asesorar la implementación de sus recomendaciones, que incluían la creación de una junta de planeación nacional. En 1952 Albert Hirschman (1915-2012) fue contratado por el banco central de Colombia como asesor de su junta, con vínculos con el Banco Mundial.

Este artículo describe la forma en que Currie y Hirschman influyeron en las primeras operaciones del Banco y en la reflexión más amplia sobre la teoría y la política del desarrollo económico.

\section{LA MISIÓN DEL BANCO MUNDIAL DE CURRIE EN COLOMBIA Y SUS CONSECUENCIAS}

Currie, nacido en Canadá, era sumamente adecuado para el papel de jefe de la misión. Estudió y enseñó en Harvard de 1925 a 1934, antes de entrar al gobierno de Estados Unidos como uno de los "cerebros jóvenes” de Jacob Viner en la Tesorería para aconsejar sobre la reforma del Sistema de la Reserva Federal (FED). Esto llevó a

* Profesor emérito de Economía, Universidad de Strathclyde, Glasgow, UK. Escrito presentado originalmente en la conferencia de la History of Economics Society (HES), Montreal, Canadá, junio de 2014. Traducción de Alberto Supelano. Fecha de recepción: 13 de enero de 2015, fecha de modificación: 6 de febrero de 2015, fecha de aceptación: 29 de abril de 2015. Sugerencia de citación: Sandilands, R. "La misión del Banco Mundial a Colombia de 1949, y las visiones opuestas de Lauchlin Currie y Albert Hirschman", Revista de Economía Institucional 17, 32, 2015, pp. 213-232. DOI: 10.18601/01245996.v17n32.07 
su nombramiento como consejero personal del director de la FED Marriner Eccles (1934-1939) y después como asesor económico del presidente Roosevelt en la Casa Blanca (1939-1945). Actuó como director de la Administración Económica Extranjera (1943-1944) y como emisario en China en 1941 y 1942 (donde tuvo discusiones con Chiang Kai-shek y Chou Enlai) y en Suiza, Francia e Inglaterra a comienzos de 1945. Después de la muerte de Roosevelt se retiró del gobierno para establecer una oficina de asesoría privada. Esto condujo a su contrato con el BIRD en 1949.

El equipo de la misión incluía 14 expertos extranjeros (con 16 asesores colombianos) en las principales áreas económicas y sociales (Richard Musgrave estuvo a cargo de las finanzas públicas). El equipo trabajó en Colombia de julio a noviembre de 1949 y el Informe, que se presentó al gobierno colombiano en julio de 1950, hacía énfasis en la consistencia interna de las metas y prioridades cuantitativas y cualitativas. El gobierno colombiano después contrató a Currie para (1) asesorar a un Comité de Desarrollo Económico (CDE) bipartidista creado para examinar las recomendaciones de su propio Informe (por el cual asumió la responsabilidad, en vez del Banco) y asesorar en política; (2) dirigir una Misión de Administración Pública a gran escala cuyas recomendaciones sobre la reforma ayudaran a implementar las recomendaciones de política del Comité; y (3) coordinar el Programa del Cuarto Punto del presidente Truman y un Programa de Asistencia Técnica de la ONU para Colombia. Se esperaba que la asesoría y los préstamos extranjeros fueran consistentes y ayudaran a apalancar las prioridades fijadas por el Comité.

\section{ALBERT HIRSCHMAN EN COLOMBIA}

En 1952 el Comité creó el Consejo Nacional de Planeación dirigido por Emilio Toro. Como asesor de este organismo, el Banco Mundial recomendó a Albert Hirschman ${ }^{1}$, quien hizo su primera visita a $\mathrm{Co}^{-}$ lombia el 15 de marzo, durante dos semanas. Después de firmar un contrato por dos años con el gobierno colombiano (en colaboración con el Banco Mundial), regresó el 15 de mayo vía Buenaventura, en la costa pacífica de Colombia, desde donde viajó por tierra a Bogotá,

\footnotetext{
${ }^{1}$ La biografía de Jeremy Adelman (2013) relata la huida de Hirschman desde la Alemania nazi en 1933 hasta su arribo a Estados Unidos en enero de 1941, con un cargo académico en Berkeley, seguido por su servicio en el ejército de Estados Unidos durante la guerra desde febrero de 1944, como intérprete en Italia y en los juicios por crímenes de guerra en Núremberg. Después entró al servicio del gobierno con la Junta de la Reserva Federal en Washington, hasta abril de 1952, cuando renunció para asumir su cargo de asesor en Colombia.
} 
a la que llegó días después para unirse al Consejo. El representante formal del Banco Mundial en el Consejo era Jacques Torfs, un economista belga miembro del personal del Banco. Entretanto, el Consejo también nombró a Currie como asesor formal a pesar de las dudas del BIRD, que temía, como resultó ser correcto, que Currie hiciera recomendaciones contrarias a las de "su" delegado: Hirschman.

En este punto seguiré algunas secciones de mi reseña del libro de Jeremy Adelman que se publicará en el Journal of the History of Economic Thought, junto con algunos comentarios relacionados sobre The tyranny of experts: Economists, dictators, and the forgotten rights of the poor, de William Easterly (2013), un libro que coincide ampliamente con Adelman en su crítica a Currie, y apoya a Hirschman con respecto a su influencia en Colombia y en otros lugares.

Para empezar, Adelman señala que en 1950 el gobierno colombiano convenció a Currie para que regresara como asesor en la implementación de su propio Informe con su programa de desarrollo integral diseñado para romper lo que Currie diagnosticó como círculos viciosos del subdesarrollo (con apoyo crediticio del Banco Mundial). Adelman, sin embargo, califica el Informe como "carente de vida", con demasiadas estadísticas (en oposición a los famosos aforismos y bon mots de Hirschman), y sigue a Hirschman en la crítica de la arrogancia de los "expertos" extranjeros, de quienes -supuestamente a diferencia de él mismo- se dice que menosprecian a los nacionales e ignoran sus consejos. También afirma (erróneamente) que Currie ignoró al sector privado en favor del Estado. Easterly malinterpreta aún más a Currie a este respecto (p. ej., pp. 120-121).

Para Easterly, la conferencia de Bretton Woods de 1944 (cuya fuerza directriz fue Harry Dexter White, amigo cercano de Currie) es el "pecado original" que envió "tecnócratas autoritarios" como Currie a Colombia para asesorar gobiernos fascistas corruptos poco interesados en la democracia. Supuestamente, ellos tratan a los países que visitan como "tablas rasas", e ignoran y perpetúan así su historia de opresión imperialista; y proponen planes grandiosos para el desarrollo de "la nación", en vez de apoyarse en individuos que conocen mejor sus propios intereses y en los que se puede confiar para que encuentren soluciones espontáneas a sus propios problemas si el Estado deja de interferir, excepto para dar voz a los pobres. Easterly (pp. 120-121, 346) elogia a Hirschman para inclinarse, más que la mayoría, hacia la democracia y hacia los pobres. Pero, en particular, alaba a Friedrich Hayek como máximo defensor de esta fe, mientras que Gunnar Myrdal es el centralizador arquetípico. Hay poco espacio 
intermedio, y se reserva un desprecio especial para empeños como el llamado de Paul Rosenstein Rodan a un Gran Impulso o el informe tecnocrático del Banco Mundial de Currie para un plan de desarrollo integral diseñado para romper los círculos viciosos interrelacionados de la pobreza y elevar el nivel general de vida ${ }^{2}$.

Currie y Hirschman estuvieron en desacuerdo desde el comienzo. Había algo de celos así como cierta inseguridad de Hirschman por el hecho de que Currie ya tenía más experiencia y conocimientos sobre Colombia (y otros lugares). Pero el conflicto involucraba profundos desacuerdos sobre programas o proyectos de crédito, proyectos "sociales" o proyectos "productivos directos", sobre la asesoría y sobre la política monetaria. Este desacuerdo -así como sus choques de personalidad- se documenta plenamente en Alacevich (2009), quien da una explicación más equilibrada que Adelman de las fortalezas y debilidades respectivas de los enfoques teóricos de ambos protagonistas, y de su efectividad política. Veremos que Adelman minimiza las críticas colombianas y del Banco Mundial a la asesoría y la personalidad de Hirschman.

El 13 de mayo de 1952 Robert Garner, vicepresidente del Banco, le escribió a Emilio Toro sobre el deseo de Toro de contratar otros asesores del Consejo: "Pensamos firmemente que solo debe haber un 'Asesor Económico' de la Junta [Hirschman] y que los demás economistas empleados por la Junta deben trabajar bajo su dirección y supervisión”. Como señala Alacevich (pp. 53-55), Toro aún esperaba que el Banco aceptara que Currie asesorara en asuntos de administración pública, "pues ningún grado de planificación será efectivo si no hay una maquinaria administrativa apropiada para llevarla adelante; eso es una obviedad".

E1 27 de mayo Garner contestó a Toro instándolo para que no contratara a Currie, pese a "su amplia experiencia y sus obvias cualidades intelectuales", porque "no es un destacado experto en el campo de la administración pública” y (más a propósito) “puede avergonzar a Hirschman". Sin embargo, Alacevich no menciona que Garner dejó la puerta abierta en una postdata: "las consideraciones que he mencionado no necesariamente se aplican al nombramiento de Currie como asesor especial de la Junta en algún aspecto particular de sus problemas". Cuando Currie quedó libre de otros compromisos, en agosto, Toro siguió adelante y lo mantuvo como asesor.

2 Currie después desarrolló estas ideas en Operación Colombia (1961), en un "plan de avance" relacionado en Desarrollo acelerado (1966) y en su Plan de las cuatro estrategias (1972), adoptado oficialmente por el presidente Misael Pastrana como plan nacional de Colombia para 1972-1974. 
Como Garner predijo, Toro luego buscaría el consejo de Currie en una amplia gama de problemas, provocando las "resistencias" que Garner temía (inevitables, pensaba Currie, para lograr algo que valiera la pena). Días después de que Currie se uniera al Consejo, Hirschman escribió una angustiada carta (el 23 de agosto) a Richard Demuth, del Banco. Allí aludió a la carta de Garner a Toro del 13 de mayo, confirmando esos temores.

\section{PRIMERASTENSIONES DE LOS PROTAGONISTAS, Y ACLARACIÓN DE LA HISTORIA}

Alacevich (pp. 56-57) y Adelman (p. 302) citan apartes de otra carta de Hirschman, esta vez a Burke Knapp del Banco, del 20 de septiembre de 1952:

Esta es la segunda carta que te escribo en tres días. Estoy muy feliz por no
haberte enviado la primera, que trataba en detalle las cosas desagradables que
han surgido aquí con respecto a la participación de Currie en la labor del
Consejo de Planeación. Al final de esa carta, te comentaba que aún confiaba
en que podría manejar la situación por mí mismo, pero añadía que no vería
mal un poco de ayuda del Banco. Tal como sucedieron la cosas, Currie se
encargó de resolver todo cometiendo uno de esos errores garrafales que aquí
no se perdonan [...] Visto en retrospectiva, todo el episodio recuerda los Cien
Días de Napoleón, jcon la afortunada diferencia de que el regreso de Currie
duró la mitad del tiempo!

Al final, Currie duró mucho más tiempo del que Hirschman esperaba. En un extracto de esa misma carta que no citan Alacevich ni Adelman, Hirschman escribió que había recibido "noticias" del miembro del Consejo Rafael Delgado Barreneche (no del presidente del Consejo Emilio Toro que entonces estaba en el extranjero) del "retiro definitivo [de Currie] del personal del Consejo". Párrafos más adelante, escribió: "Toro nunca ha aceptado los términos de la carta [de Garner del 13 de mayo], quizá en parte debido a un deseo inconsciente de institucionalizar el conflicto". Y, más adelante: "Ahora que Currie está fuera, a Toro le gustaría reproducir la misma situación de otra manera”. Hirschman trataba de impedir que Toro nombrara otra persona que pudiera amenazar su plena autoridad como economista jefe, pero estaba equivocado, y no importa cuál pueda haber sido el "error garrafal" de Currie, el escándalo amainó pocos días después; al menos eso es lo que se puede deducir del registro inédito de Currie de su participación en la labor del Comité y del Consejo en 1950-1953.

Estos son otros dos extractos de la carta de Hirschman del 20 de septiembre que Alacevich sí cita: 
Estoy convencido de que a nuestros amigos colombianos no les importa mucho la posibilidad de que se agrave el conflicto entre el personal asesor del Consejo. Les gusta enfrentar a un experto extranjero contra el otro: [...] esto les permite reverenciar la opinión de los expertos extranjeros y al mismo tiempo les sirve de coartada para hacer exactamente lo que quieren.

Y:

No renuncié a mi cargo en la Reserva Federal para asesorar sobre el aumento o la reducción de los márgenes de reservas en Colombia. Como no tengo ninguna intención de establecerme aquí como experto puramente monetario y examinar proyectos solo desde el punto de vista de su compatibilidad con la estabilidad monetaria, es aún menos posible que la planta de personal propuesta dé lugar a buenas relaciones de trabajo de lo que podría ser el caso.

Sin embargo, Alacevich señala que Currie $(1981,180)$ “expresó una opinión mucho más positiva de los enfrentamientos dentro del Consejo: 'las discusiones sobre los memorandos de política de corto plazo eran enérgicas y minuciosas, y preparaban a los miembros del comité para sus reuniones con el presidente". Cita que toma del capítulo 15 ("El marco organizativo para la asesoría") de El papel de los asesores económicos en los países en desarrollo. Este capítulo ayuda a explicar la disputa de Currie con Hirschman sobre las reformas administrativas; específicamente sobre por qué prefería que la División de Presupuesto se trasladara a la Oficina del Presidente, como en Estados Unidos desde 1939, con comentarios sobre el lugar del Consejo de Asesores Económicos del Presidente de Estados Unidos, creado en 1946.

Pero las notas de Currie sobre la historia de 1952-1953 ilustran con detalles más personales el carácter de la animosidad mutua entre Currie y Hirschman ${ }^{3}$, y dan una imagen más completa. Por ejemplo, el 4 de septiembre de 1952, Currie escribió:

Mientras me preparaba para la Misión a Caldas en mayo de este año, se creó el Consejo Nacional de Planeación. El doctor Toro estaba muy ansioso de que me desempeñara como asesor del Consejo y, en la última parte de mayo, me preparó varios memorandos sobre política y control monetario [...] Sin embargo, mientras tanto el Banco había nombrado a Al Hirschman como economista jefe del Consejo y había cerrado un contrato por dos años.

Toro estuvo enfermo durante un mes y a finales de julio creía que el Consejo estaba mal encaminado. Estaba muy ansioso de que me asociara al trabajo e imprimiera el ritmo que teníamos en el Comité de Desarrollo Económico. Dijo que había tratado el asunto con Robert Garner del Banco Mundial y que Garner había dicho que era, por supuesto, decisión del Consejo pero que temía que hubiera dificultades entre Currie y Hirschman pues Currie parecía crear resistencias. Toro dijo que si bien me decía esto, no quería crearme un complejo sino que quería que, como antes, hiciera las críticas o recomendaciones que pensara que exigía la situación. Se iba a explicar a Hirschman

${ }^{3}$ Estas notas, tituladas "Personal notes on the history of the World Bank in Colombia", se encuentran en la colección de escritos de Lauchlin Currie, biblioteca de archivos de la Universidad de Duke, [http://library.duke.edu/rubenstein/ findingaids/currie/]. 
que manejaría principalmente los asuntos de administración pública y que yo asistiría a las reuniones del Consejo que quisiera, aunque no estaba obligado a asistir a todas [...]

Empecé a trabajar con el Consejo el 12 de agosto, y a los dos días presenté el largo memorando sobre la labor y el programa del Consejo y la lista del personal necesario. Esto dio lugar al primer conflicto con Hirschman. Él había preparado un memorando que aceptaba la sugerencia del Banco de que necesitábamos dos economistas, uno para el trabajo en cuentas nacionales y uno en proyectos de inversión. Esta provenía de [Richard] Demuth pero supongo que fue escrita por Torfs. En el Consejo, en vez del economista estadístico asistente que especifiqué, Hirschman abogó por un economista experto calificado en las técnicas de diversos proyectos industriales. E1 Consejo lo descartó y llegué a un compromiso con Hirschman sobre un economista general.

E1 día siguiente discutí con Hirschman la conveniencia de evitar desacuerdos en el Consejo y sugerí que era una sana precaución leer los memorandos de cada uno antes de someterlos a discusión.

La siguiente entrada, fechada el 16 de septiembre, es claramente relevante con respecto a la carta de Hirschman a Burke Knapp del 20 de septiembre. Dice así:

Hirschman y yo después nos enredamos en la política monetaria. Descubrí que casi lo primero que hizo a su llegada fue criticar mi esquema de cuotas de redescuento. Presentó al Comité un memorando sobre la política monetaria actual que yo no había visto antes. Hice algunos comentarios sobre este y después discutí con él la conveniencia de añadir algunas recomendaciones positivas sobre la reducción del $40 \%$ de la exigencia de reservas, llegando a un acuerdo sobre una serie de medios de pago y la fijación de una meta de estabilización de los medios de pago a partir de julio. Como parecía que él no las redactaría, yo las escribí. Cuando se presentó su escrito revisado contenía algunos de estos puntos. Infortunadamente, el doctor Toro había visto mi página e insistió en leerla. H. se molestó mucho y fue a quejarse con los miembros del Consejo individualmente. Resultó que al presidente le gustó mucho la sugerencia sobre la exigencia de reservas y el Banco de la República poco después tomó medidas para restablecer exigencias uniformes. El escrito de $\mathrm{H}$. originalmente contenía el pronóstico específico de que los depósitos oficiales disminuirían en tantos millones y los préstamos a particulares en tantos millones. Yo sugerí omitir las cifras específicas, lo que también resultó ser una medida afortunada.

La siguiente dificultad fue sobre el memorando de $\mathrm{H}$. acerca del probable impacto de las operaciones fiscales del gobierno sobre la estabilidad. Él usó las cifras de presupuesto ordinario de 1952, que son inútiles para este propósito $[\ldots]$

H. me preguntó si yo no pensaba que era un error tratar de racionalizar al gobierno colombiano [como en el informe de la Administración Pública de Currie] y que probablemente era mucho mejor tener muchos pesos y contrapesos y entidades independientes. También cuestionó la conveniencia de transferir la Oficina de Presupuesto a la Oficina del Presidente con base en que el sistema inglés funcionaba muy bien con el Presupuesto en el Tesoro [...]

[Torfs] se encontró muchas veces con H., y H. le dijo al Consejo que a la Misión [del Banco Mundial] le gustaría reunirse con él. Al final, Torfs solo 
se apareció con una declaración preparada sobre "lo que el Banco esperaba que hiciera el Consejo" 4 .

E1 29 de septiembre, Currie, que obviamente aún se mantenía en el Consejo, escribió: "hice mi trabajo sobre la extensión del crédito agrícola a la ganadería y como es usual entré en conflicto con Hirschman. Él estaba muy dispuesto a arriesgarse a la inflación para complacer a Toro".

Y el 7 de octubre resumió las discusiones en el Consejo sobre un proyecto de ley que destinaba el 5\% de los depósitos bancarios exclusivamente a préstamos a la ganadería, mencionando dos memorandos que había enviado sobre el tema. Parece ser que Currie se opuso por razones relacionadas con su bien conocida crítica a la teoría de los préstamos comerciales o títulos reales del banco central con su enfoque en el crédito y no en la oferta monetaria (la cual supone que los créditos de corto plazo no son inflacionarios, a diferencia de los préstamos de largo plazo) (ver, p. ej., Currie, 1931, 1934). Además, la fungibilidad del crédito hace indeterminado el uso final de los créditos "selectivos" y forzosos. Sin embargo, hizo algunas propuestas para contrarrestar los peligros inflacionarios modificando la exigencia de reservas bancarias y un mayor compromiso con el control monetario. Él escribió:

Después de que se leyó mi escrito, Hirschman hizo un breve discurso diciendo que si queríamos hacer reformas bancarias podríamos gastar varios meses pero que él suponía que el Consejo quería hacer algo por la ganadería y que el plan con este propósito ya se había elaborado. Toro intervino enérgicamente diciendo que estaba de acuerdo el 100\%. Marulanda también lo apoyó y, para sorpresa mía, Delgado capituló y solo dijo que le gustaría discutir algunos puntos teóricos conmigo más tarde. Los demás pueden ser disculpados, pero Hirschman sabe lo suficiente para entender de lo que yo estaba hablando y que yo tenía la solución correcta.

En un memorando posterior de cuatro páginas, "El trabajo del Consejo”, del 10 de octubre de 1952, Currie enumeró los cuatro memorandos que Hirschman había enviado al Consejo en agosto y septiembre: (1) sobre política monetaria; (2) sobre política fiscal; (3) sobre "un método para obtener un gran préstamo del Banco Internacional relacionado con la nueva Corporación Aeroportuaria", del que Currie dijo: "no incluía ningún argumento acerca de si el préstamo era necesario [...] o una prioridad"; (4) sobre el crédito a la ganadería. Currie los criticó y los comparó con los trece memorandos que él mismo había enviado desde agosto. Currie escribió mordazmente sobre la contribución de Hirschman a las deliberaciones de Consejo acerca del crédito agrícola:

${ }^{4}$ Sin duda, a Easterly esto le entusiasmaría como evidencia del "pecado original" de la tiranía del Banco Mundial. 
E1 memorando del doctor Hirschman sobre crédito a la ganadería propuso abandonar la propuesta anterior del Consejo de modificar la exigencia de reservas del $40 \%$ y contemplar (en efecto) la inversión forzosa de la diferencia entre la exigencia normal de reservas y la exigencias del $40 \%$ de reservas en bonos de la Caja Agraria, después de decir que el principio de inversión forzosa era muy indeseable.

Entretanto, Jacques Torfs fue enviado por el banco como asesor del Consejo, y en su primer informe a Burke Knapp del 30 de octubre de 1952 lamentó que Enrique Peñalosa, un hombre "de gran competencia" [y después político notable], se había "unido totalmente al doctor Currie y, por tanto, se opone a Hirschman”. Añadió que Hirschman está "totalmente desanimado y parece paralizado por la existencia del doctor Toro y del doctor Currie. Los miembros del Consejo dicen en forma unánime que no ha tenido el desempeño que se esperaba de él”.

Igualmente reveladora es una franca carta de Emilio Toro a Robert Garner del 28 de noviembre de 1952, en la que (con el miembro del Consejo Jesús María Marulanda) defendió enérgicamente a Currie como líder, contra Hirschman, quien "es un buen hombre en su limitado campo de asuntos monetarios, pero como Director de Programas, para planificar el desarrollo de un país en todos sus aspectos, tiene deficiencias, muchas deficiencias. Carece de amplitud de conceptos, de liderazgo, iniciativa y personalidad, y tiene dificultades para expresar y obtener consideración de sus ideas". Toro llega a decir que al comparar los logros de Currie y Hirschman, "me siento consternado". También subrayó que Currie tenía pleno apoyo del presidente Roberto Urdaneta Arbeláez.

Adelman no reporta esto, salvo para decir que Toro "parece haber sentido disgusto por las modestas miras de Hirschman” (p. 301). En su respuesta a Toro, a nombre del Banco, del 3 de diciembre de 1952, Burke Knapp (con endoso de Robert Garner) siguió con la preocupación de que Currie continuara influyendo en el Consejo.

\section{HIRSCHMANY CURRIE SOBRE LA ECONOMÍA DEL DESARROLLO}

En junio de 1953 la labor del Consejo fue interrumpida por un golpe de Estado militar pero siguió adelante. Currie se retiró poco después de la consultoría económica y se dedicó a la agricultura de tiempo completo, hasta el retorno del gobierno del civil después de 1958. Cuando terminó su contrato de dos años, en abril de 1954, Hirschman se quedó en Colombia como asesor privado, principalmente en proyectos individuales, hasta 1956; pero después visitó a América Latina con frecuencia. 
En 1956 solicitó ayuda a la Fundación Rockefeller para establecer su propio centro de investigación privado, pero le fue negada en razón de que la fundación no apoyaba empresas lucrativas. Por suerte, Yale llegó al rescate con una beca no docente de un año, que la Fundación Rockefeller amplió un año más hasta 1958, cuando Yale publicó su influyente Estrategia del desarrollo económico, basada en gran medida en su experiencia colombiana. Esta le dio fama y le abrió las puertas para otros nombramientos en la Ivy League, como Harvard, Stanford y Princeton. Al dejar Yale fue contratado por Columbia, donde solo debía dar una clase a la semana. Adelman reporta, de modo casi conmovedor, que incluso esta ligera carga docente era una pesadilla visceral para Hirschman. Un entrevistado lo describió como un profesor "catastróficamente malo", y (a diferencia de Currie, quien amaba la enseñanza) fue mentor de muy pocos estudiantes. Esto contrasta con su asombroso don y su pasión por la palabra escrita, y con su gusto por la buena conversación. Por suerte para él, encontró maneras de librarse de la enseñanza durante buena parte de su carrera académica.

Adelman también describe con elocuencia la desilusión de Hirschman con las ideologías extremistas, resultante de sus traumáticos encuentros personales con el fascismo en Alemania, Italia y España, el cual provocó su antítesis marxista igualmente dictatorial. No solo en La estrategia sino también en mucha de su obra posterior defendió un campo intermedio para lo que llamó el "posibilismo" optimista del "afán reformista" (reform-mongering).

Esto explica en parte su enfrentamiento con Currie en Colombia sobre un plan maestro dentro del cual fijar las prioridades de los proyectos individuales. De acuerdo con lo que Paul Rosenstein Rodan llamó el "Gran Impulso" para superar las trampas del equilibrio de bajo nivel y los círculos viciosos, Currie, como hemos visto, había propuesto un programa coordinado de estabilización monetaria y cambiaria junto con programas sociales y de infraestructura, y las reformas administrativas necesarias.

Adelman califica de "confuso" el enfoque en la reforma administrativa (p. 301), aunque hemos señalado que Toro y el Consejo pensaban de modo diferente. Todas las propuestas de Currie fueron diseñadas para integrar la red de transportes y comunicaciones del país y alentar mayor competencia, movilidad y urbanización a fin de ampliar el tamaño efectivo del mercado nacional, entonces muy fragmentado. Esto incrementaría la especialización y la intensidad del capital, que Adam Smith consideraba esenciales para la riqueza de las naciones, provocando un crecimiento endógenamente autosostenido en vez de 
un crecimiento que se agota por sí mismo5. (Adelman se equivoca al afirmar que Currie, a diferencia de Hirschman, subestimó al papel del sector privado en todo esto.) Currie subrayó la necesidad de seguir la dirección natural de las elasticidades ingreso y precio de la demanda promoviendo la migración de trabajadores de la agricultura de productividad nula y baja a la industria y los servicios urbanos de productividad más alta, como medio indirecto pero más efectivo para aliviar la pobreza rural.

En cambio, Adelman señala con entusiasmo que Hirschman dedicó sus Viajes hacia el progreso (1963) a Carlos Lleras Restrepo (después presidente de Colombia) por su enfoque directo -algunos dirían simplista- de la pobreza rural mediante la creación en 1961 de un Instituto de Reforma Agraria diseñado para repartir las grandes haciendas, promover la colonización (costosa) y extender la Revolución Verde. Había poca conciencia de que el aumento de la productividad agrícola de los beneficiarios acentuaría notablemente la presión competitiva sobre los agricultores menos favorecidos. Se corre el riesgo de cometer una falacia de composición cuando se generaliza a partir de estudios de caso microeconómicos y de las petites idées de Hirschman. $\mathrm{E} 1$ gran incremento de la productividad de algunos no se traduce en incrementos similares de la producción total. Debido al aumento relativamente lento de la demanda, los incrementos de productividad desplazan aún más agricultores a las filas de los desempleados, en ausencia de políticas de urbanización mucho más vigorosas que las que Carlos Lleras apoyaba.

Se podrían hacer críticas similares al posterior entusiasmo de Hirschman (1983) por el microcrédito subsidiado y las cooperativas de tricicleros desempleados disfrazados en República Dominicana en 1983 (Adelman, 586), o por los artesanos en el pueblo "selvático" (sic) colombiano de Raquira (Adelman, 582) (no hay selva a 2.200 metros) cuando estaba saturado el abarrotado mercado de sus productos.

Pero Hirschman rechazó la noción de desempleo disfrazado y se sintió “abatido" cuando en 1979 Arthur Lewis, y no él, ganó el premio

\footnotetext{
${ }^{5}$ Currie más tarde (p. ej., 1981, 1997) refinaría el artículo seminal de su mentor en Harvard, Allyn Young (1928), sobre el progreso económico, en el cual la demanda recíproca es la fuerza clave que impulsa la especialización en sus diversas formas modernas y genera lo que Currie llama rendimientos crecientes macroeconómicos, distintos de las economías de escala microeconómicas. Estos rendimientos crecientes generan un "efecto multiplicador youngiano" que sostiene endógenamente el crecimiento, salvo que sea contrarrestado por choques exógenos negativos, incluidos los errores de política anti mercado. Este efecto multiplicador real difiere y puede ser contrario al multiplicador keynesiano más conocido que se representa en términos monetarios, y puede o no agotarse en aumentos de precios. Esto se explica en Currie (1983).
} 
Nobel por su modelo del desarrollo de la economía con excedentes de trabajo. Pues, como dice Adelman: "Si se iba a dar un Nobel a un economista de desarrollo, solo habría uno. Lewis lo obtuvo". De hecho, ese año Theodore Schultz de Chicago compartió el premio por su notable obra sobre el desarrollo de la agricultura tradicional (intrínsecamente racional). Aunque Schultz también era escéptico del desempleo disfrazado, Hirschman despreciaba su "ideología" del hombre económico racional de la escuela de Chicago, en la agricultura como en otras partes. (Hirschman y Adelman son también mordaces sobre el papel de la escuela de Chicago en Chile después de Allende, pero no mencionan que Chicago fue una probable reacción a los excesos monetarios de Allende.) De modo que Hirschman rechazó el gran impulso y otros planes maestros.

\section{HIRSCHMAN Y CURRIE SOBRE EL “GRAN IMPULSO” DE PAUL ROSENSTEIN-RODAN ${ }^{6}$}

A comienzos de los años cincuenta Ragnar Nurkse consideraba que el gran impulso era consistente con el "crecimiento balanceado", al que entendía como la promoción simultánea y coordinada de todos los sectores. Tibor Scitovsky (1954) dio una definición más útil del "balance": el equilibrio entre el crecimiento de la oferta y el crecimiento de la demanda de sectores cuyas elasticidades de demanda potenciales difieren en forma significativa. A diferencia de Nurkse, también subrayó las oportunidades del comercio internacional ${ }^{7}$. Es entonces erróneo caricaturizar el crecimiento balanceado como el llamado a que todos los sectores crezcan al mismo ritmo o como una negación de la validez de dar prioridad a los sectores que enfrentan la mayor demanda potencial. Hay mucho que los países latinoamericanos podrían haber hecho a este respecto, de haber tenido mejor asesoría. Por ejemplo, Currie mostró que podrían haber hecho más para evitar las distorsiones no naturales asociadas al mal manejo monetario y la inflación crónica, sin achacar la culpa a los inevitables obstáculos estructurales o a los movimientos de los términos de intercambio "intrínsecamente adversos".

${ }^{6}$ Rosenstein-Rodan participó en parte del trabajo preparatorio para la misión del Banco Mundial a Colombia de 1949 (Alacevich, 22) y era conocido personalmente por Hirschman y Currie.

7 Currie (1966) criticó a Nurkse y a otros de los primeros economistas del desarrollo (incluidos los que estaban influidos por el modelo de Harrod-Domar) por la excesiva concentración en las proporciones de ahorro e inversión agregadas, que desviaba la atención de (a) la dependencia de la inversión de la demanda final de los consumidores y (b) la muy distinta demanda potencial para los diferentes sectores, incluidas las exportaciones, en diferentes escenarios de política. 
La tesis de Hirschman en su Estrategia de 1958 y después en El comportamiento de los proyectos de desarrollo (1967) era que se debía preferir un crecimiento deliberadamente desbalanceado de la oferta y la demanda. Como creía que el recurso más escaso en los países en desarrollo era "la capacidad para tomar decisiones" y que "la actividad directamente productiva” y no el "capital social fijo" era estratégica, el sector privado debía ser motivado por las tensiones y oportunidades que una estrategia desbalanceada podía crear deliberadamente (como si no hubiese ya bastantes tensiones, incluso con una senda de crecimiento balanceado planeada). Esto también lo llevó a adoptar una actitud "mucho más tranquila" y menos alarmista hacia el problema de la población que la de Harvey Leibenstein, cuyas "trampas" de población requieren "un enorme salto para salir de ellas"(Hirschman, 1958,182). Más célebre fue su novedoso "principio de la mano oculta": que los planificadores debían exagerar deliberadamente los beneficios y subestimar los costos cuando asesoraban a inversionistas privados supuestamente muy adversos al riesgo de invertir su dinero (no el de Hirschman ni el de los planificadores). Adelman no cuestiona si esto puede ser no solo mala economía sino moralidad aún peor.

Sin embargo, era original y encantador ("aun los escépticos se desmayaban ante su prosa”, p. 654). La elaboración de esta tesis, junto con su adopción del criterio de "encadenamientos hacia atrás y hacia adelante" para seleccionar proyectos, le aseguraría una generosa financiación para el trabajo de campo y la observación de estudios de caso de proyectos de desarrollo individuales que llenarían sus cuadernos de notas con petites idées y aforismos flaubertianos y montaigneanos. Estos se elevaron a una grande idée: que las grandes ideas son malas ${ }^{8}$.

Adelman resalta la "centralidad de los efectos secundarios"(Hirschman, 1967, cap. 5) en la forma de esos encadenamientos hacia atrás y hacia adelante y de tensiones (p. 401). Así, el fracaso se puede considerar como un éxito. Por ejemplo, Hirschman (1957) defendió con cautela los proyectos intensivos en capital y dio respaldo retrospectivo a una controvertida decisión reciente de ceder ante los grupos regionales de presión (contra la recomendación de Currie, del Comité de Desarrollo Económico e incluso del Banco Mundial ${ }^{9}$ ), en la aprobación de una gran siderúrgica integrada altamente subsidiada en Paz del Río, en una región pobre y remota de Colombia. Hirschman veía el acero como un excelente ejemplo de un sector con muchos eslabones

${ }^{8}$ Excepto quizá su propia defensa a finales de los años cuarenta y comienzos de los cincuenta, mientras estaba en la FED, de unos Estados Unidos de Europa con una moneda común y su propio ejército; ver Adelman (2013, 276-280).

${ }^{9}$ Como se documenta en Currie (1981, cap. 2). 
hacia atrás y hacia adelante que podían alentar la innovación en otros sectores ${ }^{10}$. Sin embargo, esto ignora los desplazamientos negativos paralelos. Aquí, esos desplazamientos se debían a la mala calidad del mineral, a los exorbitantes costos de minería y transporte y a la prohibición de acero importado mucho más barato. Otras industrias que usaban acero, los contribuyentes y los consumidores sufrieron las consecuencias durante varias décadas. Hirschman también ignoró los consiguientes menores ingresos derivados de una menor demanda efectiva de todos los sectores de la economía. El sesgo en favor de la producción de acero de muy alto costo y baja calidad y en contra de la construcción es totalmente opuesto al enfoque de las elasticidades reales y potenciales de la oferta y la demanda de Currie.

Pero los intereses políticos y regionales prevalecieron, y Hirschman (1957) escribió con demasiado optimismo que este proyecto “probablemente llegará a ser [...] un paso efectivo en el desarrollo en comparación con cualquier programa para proporcionar a esa zona abundante capital social fijo cuya capacidad puede mendigar por largos años"11. Esto concordaba con su preferencia por las "actividades directamente productivas" frente al capital social fijo. También pensaba que ceder ante los intereses de las regiones más pobres podría generar desequilibrios que estimularan reacciones de promoción del crecimiento en otras partes, otro ejemplo de una estrategia de crecimiento desbalanceado que podría sacar un éxito del fracaso.

Currie también pensaba que las políticas de "equilibrio regional" se asemejaban demasiado a la propensión de los geógrafos a "rellenar espacios en un mapa" y no a la eficiencia económica, pero su lógica era muy diferente de la de Hirschman a este respecto. Ante la extensión de la pobreza en todo el país su solución se basaba más en atraer a los trabajadores rurales subempleados a ciudades dinámicas y no a lugares con mucho menos futuro. En cambio, Hirschman $(1958,188)$ parecía tener poco entusiasmo por la migración.

Sin embargo, Alacevich $(2009,101)$ considera que Hirschman y Currie realmente tenían puntos de vista convergentes. Pero el mejor ejemplo que puede dar es que aunque Currie se opuso a la siderúrgica de Paz del Río, estuvo a favor de una planta eléctrica más pequeña en la ciudad costera de Barranquilla para transformar chatarra de metal importada. Cuando los políticos bloquearon esta opción, él y el Comité intentaron limitar el daño construyendo gradualmente la

${ }^{10}$ Ver también Hirschman (1958, 147 y 204).

${ }^{11}$ Cuando solicitó financiación al Banco Mundial, Hirschman mencionó que podría incluir el caso de Paz del Río como uno de sus "Proyectos de desarrollo observados", pero lamentablemente al final no lo incluyó. 
nueva planta de Paz del Río, "ligando así su desarrollo al aumento de la competencia y de la participación en el mercado”. Alacevich continúa:

Esto habría limitado la carga de su desafortunada ubicación y dejado que el negocio ganara fuerza a pesar de esta desventaja inicial. Este razonamiento no era en realidad muy diferente del esfuerzo de Hirschman por encontrar las "racionalidades ocultas" del proceso de crecimiento. Gracias a ellas, la economía de un sector o un país es impulsada a nuevas sendas de crecimiento que antes eran invisibles o impredecibles [...]

La ruptura aparentemente irreconciliable entre Hirschman y Currie tuvo que ver con sus marcos de referencia respectivos. A partir de premisas opuestas, en un entorno más complejo e interrelacionado de lo que parecía a primera vista, a menudo llegaron a conclusiones similares (ibíd., 101-103).

Mi argumento es que el desacuerdo era más fundamental. En una larga nota de pie de página relacionada con el pasaje citado, Alacevich dice:

Quizá hubo otros desacuerdos entre Currie y Hirschman. Según Krugman, Hirschman basó su concepto de "eslabonamientos hacia atrás" en "la idea de economías de escala a nivel de la planta individual [que] se traduce en rendimientos crecientes a nivel agregado a través de las economías pecuniarias externas" (1993, 22). Ramesh Chandra y Roger Sandilands (2005) sostienen, por el contrario, que la importancia de las economías de escala es marginal comparada con la de los rendimientos crecientes. Sandilands interpreta la formulación de Hirschman como una referencia a las economías tecnológicas externas que solo se refiere marginalmente a las economías pecuniarias externas, las cuales estaban en el centro del análisis de Currie. Específicamente, Sandilands sostiene que los encadenamientos "hacia atrás" y "hacia adelante" de Hirschman tienden a ser principalmente tecnológicos (enmarcados en una relación insumo-producto), mientras que Currie se centra en el tamaño de la demanda potencial [...] Sea como fuere, me parece que los diferentes puntos de vista sobre lo que estaba en la base de "los encadenamientos hacia atrás" de Hirschman demuestran que el debate teórico puede magnificar diferencias que a nivel práctico son mucho menos definidas y no tan lejanas (ibíd., 176-177).

En realidad mi desacuerdo quizá sea mejor explicado con referencia a un punto relacionado que Alacevich señala:

Es posible que surgieran desacuerdos sobre la adecuación de la producción
intensiva en trabajo (preferida por la misión Currie) o intensiva en capital (pre-
ferida por Hirschman). La preferencia de Hirschman se basaba en el principio
de que una fuerza de trabajo no calificada para la manufactura podía ser más
productiva si la producción se centraba en el proceso (normalmente intensivo
en capital, como la producción de acero) y no en el producto (normalmente
intensivo en mano de obra, como la construcción). Pero, aunque interesantes
e incluso importantes, estos no eran grandes desacuerdos (ibíd., 102).

En la comparación de la industria siderúrgica con el sector de la construcción, a Hirschman le interesaba destacar la mayor importancia de los encadenamientos hacia atrás. Los encadenamientos hacia adelante solo eran significativos hasta la etapa del producto final. Puesto que una vivienda es un producto final, su construcción no tiene encadenamientos hacia adelante. Esta parece ser la razón 
para que Currie haya escrito (en un manuscrito inédito de 1970, a Rosenstein-Rodan) que Hirschman no entiende el significado de la ley de Say y de la demanda real, y por ello su concepción del tamaño del mercado -solo en términos de encadenamientos- es mucho más limitada que la de Adam Smith (1776) o la de Allyn Young (1928).

Si una demanda latente de vivienda se actualiza mediante un estímulo a los ahorros que ahora se dirigen a la construcción de vivienda, en el proceso se obtienen mayores ingresos reales. Estas ganancias, respaldadas por producción real, luego se gastan en (o se intercambian recíprocamente por) el producto de otros sectores. Estos gastos generan naturalmente lo que se puede llamar economías pecuniarias externas laterales para otros sectores que ahora pueden vender más alimentos, vestuario, muebles, etc., así como más inversiones en vivienda, financiadas con el aumento de los ahorros provenientes de los mayores beneficios y salarios obtenidos en la producción para la cual existe y se puede actualizar la demanda final latente.

Como subrayan Chandra y Sandilands (2005), siguiendo a Currie, las economías pecuniarias externas no indican una falla de mercado que se debe internalizar mediante la coordinación central integral de los sectores, como sostenía Rosenstein-Rodan. Por el contrario, las fallas de mercado específicas y las distorsiones asociadas, por ejemplo, por la inadecuada movilidad del trabajo y la inflación, impiden la plena explotación de esas economías externas naturales y benéficas. Fue por estas razones que Currie (1970) sostuvo que Hirschman no entendía el punto central de la defensa de Rosenstein-Rodan de un Gran Impulso y que su aliento al debate crecimiento balanceadodesbalanceado fue una distracción innecesaria. El punto era cómo diseñar un Gran Impulso: (1) mediante un programa de inversión integral, con énfasis en la formación de capital total à la Nurkse y à la Rosenstein-Rodan, o (2) por medio de la promoción selectiva de sectores "líderes" potencialmente grandes basada en la eliminación de obstáculos antinaturales a la liberación de una demanda altamente elástica pero hasta ahora solo latente.

Currie escribió:

Hirschman argumenta que "la ventaja de un avance oscilante" frente al
"crecimiento balanceado", en el que cada actividad se expande en perfecta
consonancia con cualquier otra, es que deja amplio margen para las decisiones
de inversión inducida y por tanto economiza [...] tomar decisiones genuinas"
(p. 63). Este es un asunto totalmente falso. La posibilidad de una expansión
donde cada actividad esté en perfecta consonancia con cualquier otra en un
país en desarrollo ( io desarrollado!) es ridícula. Los países en desarrollo no
deben estar limitados a tomar decisiones de inversión "correctas" a causa de
la posible desaparición de las ganancias o debido a que la tendencia de las

Revista de Economía Institucional, vol. i7, N. ${ }^{\circ}$ 32, Primer Semestre/20i5, PP. 21 3-232 
ganancias a igualarse desanimaría aún más la inversión. Parece más probable que cuanto mayor sea el número de inversiones no rentables, menor será el incentivo para hacer nuevas inversiones. Además, la distinción entre una decisión de inversión "inducida" y tomar decisiones genuinas no existe.

Esta es, entonces, la respuesta de Hirschman a la posibilidad del "equilibrio del subdesarrollo”, o una tasa de crecimiento demasiado lenta. ¡No existe, puesto que los países desarrollados experimentaron avances industriales parciales, pero sí se puede romper induciendo a los prestamistas internacionales y a los capitalistas y gobiernos locales a hacer inversiones desbalanceadas ("erróneas" en términos de la demanda efectiva actual) que crean desequilibrios y tensiones, que inducen inversiones adicionales para corregir los errores, y así también economizan tomar decisiones! Esta se podría llamar la estrategia de desarrollo a bandazos, porque el progreso se parecería a lo que hacen los esfuerzos de un borracho para recuperar el equilibrio y avanzar mientras se tambalea de un lado a otro $(1970,17)$.

A diferencia de Hirschman, Currie (p. ej., 1971, 1974, 1997) fue un enérgico defensor de la vivienda como un importante "sector líder" potencial (junto con las exportaciones) capaz de romper el círculo vicioso de una lenta tendencia de crecimiento autosostenido y convertirla en una tendencia más rápida. Con ese propósito fue el "padre” reconocido de un sistema de financiación de vivienda adoptado en Colombia en 1972, mediante el cual las obligaciones (principalmente ahorros personales) y los activos (hipotecas) del sistema se indexaban por la inflación ${ }^{12}$. Esto (1) aumentó el rendimiento real de los ahorradores, con un gran efecto sobre el volumen de ahorros, y (2) redujo el problema de la "pesada carga inicial de las hipotecas" para los prestatarios cuando la tasa de interés nominal (pero no la real) se reducía con ese nuevo sistema. Así se ampliaron la oferta y la demanda del mercado. El efecto sobre la oferta de vivienda urbana tuvo gran influencia en la movilidad del trabajo, pues aceleró el traslado del excedente de trabajo rural a empleos urbanos mejor remunerados. Todo esto aumentó el tamaño real y el crecimiento del mercado, un elemento clave en el diagnóstico de Smith y Young de la principal fuente de riqueza de las naciones a través de un incremento de los incentivos y la capacidad para ampliar la división del trabajo.

El motivo principal no era cuán intensivo en trabajo era el sector de la construcción. Era, más bien, la cuestión de dónde estaba la mayor demanda real y potencial. La construcción bien puede ser de hecho relativamente más intensiva en trabajo que el acero, y usar relativamente más insumos locales que extranjeros. Pero estas eran

${ }^{12}$ También abogó por aislar la tasa de cambio de los efectos tóxicos de la inflación sobre las exportaciones netas, para explotar más plenamente la demanda externa real reprimida y así convertir las exportaciones en un segundo sector líder junto con la vivienda urbana. 
consideraciones secundarias. Su influencia positiva sobre la movilidad del trabajo era una ventaja adicional.

En sus recuerdos autobiográficos, "La confesión de un disidente" (G. Meier y D. Seers, eds., Pioneros del desarrollo, 1984), Hirschman aún hacía especial énfasis en los encadenamientos hacia atrás: la siderúrgica de Boyacá alentó la minería allí. Pero también condenó a los usuarios de acero a altos costos y mala calidad, de modo que esos "encadenamientos hacia adelante" impusieron desventajas a otras industrias, y aumentaron los precios al consumidor ${ }^{13}$. Paz del Río no es entonces un buen ejemplo de industrialización por sustitución de importaciones exitosa, acerca de la cual Hirschman era tan optimista. Es notable que en ese ensayo autobiográfico Hirschman admitiera que su intento de confesar los pecados tiende a terminar como una confesión de fe. ¡No se retractó del crecimiento desbalanceado, de la teoría de los encadenamientos ni del principio de la mano oculta!

\section{REFERENCIAS BIBLIOGRÁFICAS}

1. Adelman, J. Worldly philosopher: The odyssey of Albert O. Hirschman, Princeton, Princeton University Press, 2013.

2. Alachevic, M. The political economy of the World Bank: The early years, Palo Alto, Ca., Stanford University Press, 2009.

3. Chandra, R. y R. J. Sandilands. "The role of pecuniary external economies and economies of scale in the theory of increasing returns", Review of Political Economy 18, 2006, pp. 193-208.

4. Currie, L. "The decline of the commercial loan", Quarterly Journal of Economics 45, agosto de 1931, pp. 698-709.

5. Currie, L. The supply and control of money in the United States, Cambridge, Mass., Harvard University Press, 1934.

6. Currie, L. Operación Colombia: un programa nacional de desarrollo económico y social, Barranquilla, Cámara Colombiana de la Construcción, 1961.

7. Currie, L. Accelerating development: The necessity and the means, Nueva York, McGraw-Hill, 1966.

8. Currie, L. “The Big Push and balanced and unbalanced growth", cap. 19 de un libro manuscrito e inédito, 1970, 33.

9. Currie, L. "The exchange constraint on development: A partial solution to the problem", The Economic Journal 81, 1971, pp. 886-903.

10. Currie, L. "The leading sector model of growth in developing countries", Journal of Economic Studies N.S. 1, 1, 1974, pp. 1-16.

11. Currie, L. The role of economic advisers in developing countries, Westport, Conn., The Greenwood Press, 1981.

${ }^{13}$ En su Estrategia añadió una salvedad con respecto a los encadenamientos hacia adelante (sin que figurara destacadamente): "Es probable que la fuerza del estímulo hacia adelante sea sustancial, siempre que la demanda sea suficiente para justificar la producción doméstica" (p. 102) (cursivas añadidas). Pero en el caso del acero la demanda no era suficiente. 
12. Currie, L. "Allyn Young and the development of growth theory", Journal of Economic Studies 8, 1981, pp. 52-60.

13. Currie, L. “The 'multiplier' in economic literature”, Journal of Economic Studies 10, 3, 1983, pp. 42-48.

14. Currie, L. y R. J. Sandilands. "Implications of an endogenous theory of growth in Allyn Young's macroeconomic concept of increasing returns", History of Political Economy 29, 1997, 413-443. Traducido como "Implicaciones de una teoría del crecimiento endógeno en el concepto macroeconómico de rendimientos crecientes de Allyn Young”, Revista de Economia Institucional 15, 28, 2013, pp. 95-126.

15. Easterly, $W$. The tyranny of experts: Economists, dictators, and the forgotten rights of the poor, Nueva York, Basic Books, 2013.

16. Hirschman, A. O. "Investment policy and 'dualism' in underdeveloped countries”, American Economic Review 47, 5, 1957, pp. 550-570.

17. Hirschman, A. O. The strategy of economic development, New Haven, Yale University Press, 1958.

18. Hirschman, A. O. Development projects observed, Washington DC, Brookings, 1967.

19. Hirschman, A. O. "Review of Lauchlin Currie, Accelerating development", American Economic Review 57, 3, 1967, pp. 611-613.

20. Hirschman, A. O. Journeys toward progress: Studies in economic policymaking in Latin America, New Haven, Yale University Press, 1968.

21. Hirschman, A. O. A bias for hope, New Haven, Yale University Press, 1971.

22. Hirschman, A. O “A dissenter's confessions”, G. Meier y D. Seers, eds., Pioneers in development, Washington DC, The World Bank, 1984.

23. International Bank for Reconstruction and Development, The basis for a development plan for Colombia: Report of a mission headed by Lauchlin Currie, Washington DC, IBRD, 1950.

24. Krugman, P. "Toward a counter-counter revolution in development theory", World Bank Economic Review (Supplement: Proceedings of the Annual World Bank Conference in Development Economics 1992), 7, 1993, pp. 15-38.

25. Nurkse, R. Problems of capital formation in underdeveloped countries, Oxford, Blackwell, 1953.

26. Rosenstein-Rodan, P. N. "Problems of industrialisation of Eastern and South-Eastern Europe", Economic Journal 53, 1943, pp. 202-211.

27. Rosenstein-Rodan, P. N. "Notes on the theory of the 'Big Push", H. S. Ellis y H. C. Wallich, eds., Economic development of Latin America, Londres, Macmillan, 1961.

28. Sandilands, R. J. The life and political economy of Lauchlin Currie: New Dealer, presidential adviser, and development economist, Durham, NC, y Londres, Duke University Press, 1990.

29. Sandilands, R. J. "Solovian and new growth theory from the perspective of Allyn Young on macroeconomic increasing returns", History of Political Economy 41 (annual supplement), 2009, pp. 285-303.

30. Scitovsky, T. "Two concepts of external economies”, Journal of Political Economy 62, 1954, pp. 143-151. 
31. Young, A. A. "Increasing returns and economic progress", Economic Journal 38, 1928, pp. 527-542. 